\title{
Burden of esophageal cancer in Iran during 1995-2015: Review of findings from the Global Burden of Disease studies
}

\author{
Hojjat Rahmani ${ }^{1}$, Ali Sarabi Asiabar ${ }^{2}$, Somayeh Niakan ${ }^{3}$, Seyed Yaser Hashemi ${ }^{4}$, Ahmad Faramarzi ${ }^{5}$, Sahar Manuchehri ${ }^{1}$, \\ Ghasem Rajabi Vasokolaei ${ }^{1,6}$
}

Received: 15 Mar 2018

Published: 2 Jul 2018

\section{Abstract}

Background: Iran is located in Asian esophageal cancer belt, with age-standardized incidence rate (ASR) of approximately 7 per 100,000 for both men and women. To provide potential solution recommendations for achieving accurate estimations regarding the burden of the disease in Iran, we designed a study to assess the burden of esophageal cancer in Iran during 1995-2015 by collecting data from the Global Burden of Disease studies.

Methods: Data were extracted from the Global Burden of Disease (GBD) during 1995-2015, which were published by the Institute for Health Metrics and Evaluation. For this purpose, disability adjusted life years (DALYs), incidence, and prevalence rate were applied to report burden of esophageal cancer based on gender and age group in Iran during 1995-2015. The Cochran-Armitage and t test were used to assess statistical significance. Stata Version 13 and Excel 2016 were used for data analysis.

Results: During 1995-2015, in total, 304102 DALYs (179 562 for males vs. 124540 for females) were attributed to esophageal cancer in Iran. In both genders and all ages, the number of DALYs increased significantly from 45018 in 1995 to 74399 in 2015.

Conclusion: Esophageal cancer is still a public health issue in Iran. Most of DALYs were due to years of life lost (YLL), suggesting the need for prevention, early detection, and screening programs. P-value was statistically significant just between male and female groups $(\mathrm{p}<0.05)$.

Keywords: Esophageal cancer, Disability adjusted life years, Iran, Global burden of disease

Copyright $\odot$ Iran University of Medical Sciences

Cite this article as: Rahmani H, Sarabi Asiabar A, Niakan S, Hashemi SY, Faramarzi A, Manuchehri S, Rajabi Vasokolaei Gh. Burden of esophageal cancer in Iran during 1995-2015: Review of findings from the global burden of disease studies. Med J Islam Repub Iran. 2018 (2 Jul);32:55. https://doi.org/10.14196/mjiri.32.55

\section{Introduction}

Esophageal cancer is considered as a fatal disease in developed and developing countries. This health problem is the sixth most common cause of mortality due to cancer worldwide, with estimated 439025 deaths in 2015 (1-3). Based on GLOBOCAN 2012 data, the estimated mortality rate of esophageal cancer is 14.1 per 100000 in Eastern Asia, 12.8 in males in Southern Africa, 7.3 in Eastern Africa, and 6.2 in females in Southern Africa (1).

Iran is a country located in Asian esophageal cancer belt, with age-standardized incidence rates (ASR) of ap-

\footnotetext{
Corresponding author: Ahmad Faramarzi, ahmadfaramarzi97@yahoo.com

1. Department of Health Management and Economics, School of Public Health, Tehran University of Medical Sciences, Tehran, Iran.

2. Health Management and Economics Center, Iran University of Medical Sciences, Tehran, Iran.

3. Department of Prosthodontics, School of Dentistry, Tehran University of Medical Sciences, Tehran, Iran.

4. Fasa University of Medical Sciences, Fasa, Iran.

${ }^{5}$ Department of Public Health, School of Health, Urmia University of Medical

Sciences, Urmia, Iran.

${ }^{6}$ Scientific Research Center, School of Public Health, Tehran University of Medical Sciences, Tehran, Iran.
}

proximately 7 per 100000 for males and females, which even exceeds 100 in its high-risk area (4-6). For instance, in Golestan province, in the eastern part of the Caspian littoral of Iran, the age-adjusted incidence rate has been reported to be 100 per 100000 (World Standard Population) in the 1960s and 1970s for both genders. Other studies also showed age-standardized incidence rates of 43.4 and 36.3 for males and females, respectively during 1996$2000(7,8)$. Esophageal cancer is responsible for almost 5800 of 35000 annual cancer deaths in Iran (9). Although

$\uparrow$ What is "already known" in this topic:

In the last decade, the burden of esophageal cancer has increased in Iran, especially in males, and this cancer was the sixth most common cause of mortality due to cancer worldwide.

$\rightarrow$ What this article adds:

Esophageal cancer is common in Iran, and the majority of DALY due to esophageal cancer is related to 50-69 age group. The burden of esophageal cancer is significantly higher in males. 
survival rate for cancers has been improving in recent years, esophageal cancer remains one of the most fatal malignancies. This cancer is diagnosed at a late stage, with 5-year survival rate of $10 \%$ and $14 \%$ for males and females, respectively, in Iran and 12\% in Europe (10-12).

According to the literature relevant to esophageal cancer in Iran, studies that calculated the burden of esophageal cancer are divided into 2 groups. The first group, which is also the main group, includes studies using the number of deaths, prevalence, incidence rate, and mortality rate as indicators. These studies were designed to evaluate the epidemiology of esophageal cancer and examine the incidence, prevalence, and mortality due to cancers (1316). The second group included studies concerning disability adjusted life years (DALYs), years of life lost (YLLs), and years lost due to disability (YLD) as health gap indicators. Unlike the first group studies, these studies are rare and have been conducted at regional levels (17, 18).

Esophageal cancer has put an extensive burden on the health, life expectancy, and well-being of Iranian population, especially in northern areas. Moreover, few studies have examined the burden of disease in the general population. Therefore, the present study was conducted to report the burden of esophageal cancer in Iran during 19952015 by acquiring data from Global Burden of Disease (GBD). Furthermore, the aim of this study was to describe the burden of esophageal cancer via DALY approach, which has introduced GBD methods and is also helpful for health policy-makers. Cancer burden studies are potentially important in public health decision-making because they help detect improvements in information systems and cost-effectiveness studies.

\section{Methods}

Data were retrospectively collected from the Global Burden of Disease (GBD) during 1995-2015 and published by the Institute for Health Metrics and Evaluation (IHME). In the GBD, data are collected and analyzed by a consortium of more than 1800 researchers in more than 120 countries. Preliminary data included premature death and disability from more than 300 diseases and injuries in 20 groups separated by age and sex in 188 countries during 1990-2018. In GBD studies, a comprehensive database of death registration system, vital registration, verbal autopsy, mortality surveillance, and other sources is used to assess the outcomes of health loss, including deaths and death rates, YLLs, YLDs, and DALYs. A complete description of the data, statistical modeling, and metrics are explained in detail elsewhere (19-21).

To better characterize the burden of esophageal cancer in Iran, we needed to collect reported death number and crude incidence and prevalence rate. The incidence rate refers to the number of new cases in a fixed time period divided by the number of people at risk. On the other hand, the prevalence rate is the number of people with the disease at a given time divided by the number of people at risk. DALY is a tool developed by the World Health Organization (WHO) to measure, compare, and analyze the burden of various diseases $(22,23)$. The DALY combines time lost through premature death and time lived in states of less than optimal health, generally referred to as disability. This metric contains 2 components: years of life lost due to premature mortality (YLLs) and number of years lost due to disability (YLDs). A DALY is equal to the loss of one year of healthy life from the combined impacts of mortality and disability $(24,25)$.

The YLLs for a cause are basically calculated through the number of cause-specific deaths in an age group multiplied by a standard life expectancy at which death occurs (26). The YLDs for a particular cause were calculated by multiplying the number of incident cases by the disability weight by the average duration of the case until remission or death. The weight of disability has been reported by the WHO studies for various diseases $(27,28)$.

Stata Version 13 and Excel 2016 were used to analyze data and report DALY numbers and its components based on gender and age group during 1995-2015. To assess statistical significance according to trend, the CochranArmitage test was applied. Also, t test was used to analyze gender groups, with significance level set at $\mathrm{p}<0.05$. The age groups were categorized according to the method proposed by WHO and other studies. These groups include younger than 5 years, 5-14 years, 15-49 years, 50-69 years, and older than 70 years (29).

\section{Results}

GBD results for esophageal cancer in Iran are presented here based on the following parameters: The disabilityadjusted life years (DALYs), years of life lost due to premature mortality (YLLs), number of years lost due to disability (YLDs), death, incidence, and prevalence rate.

During 1995-2015, there were 13144 deaths related to esophageal cancer in Iran. The number of deaths caused by esophageal cancer increased in Iran from 1853 in 1995 to 3261 in 2015 in both genders. Table 1 demonstrates death number, incidence, and prevalence rate per 100000 due to esophageal cancer in Iran.

\section{DALYs and its component}

The estimated esophageal cancer in Iran during 19952015 was 304102 DALYs. Table 2 demonstrates the

Table 1. The number of death, incidence, and prevalence rate of esophageal cancer in Iran during 1995- 2015

\begin{tabular}{|c|c|c|c|c|c|c|c|c|c|c|c|c|}
\hline \multirow[t]{2}{*}{ Years } & \multicolumn{4}{|c|}{ Death Number } & \multicolumn{4}{|c|}{ Crude Incidence Per 100000} & \multicolumn{4}{|c|}{ Crude Prevalence Per 100000} \\
\hline & Male & Female & Both & $\mathrm{p}$ & Male & Female & Both & $\mathrm{p}$ & Male & Female & Both & $\mathrm{p}$ \\
\hline 1995 & 1099 & 754 & 1853 & 0.004 & 3.12 & 2.26 & 2.7 & 0.003 & 3.33 & 2.58 & 2.96 & 0.009 \\
\hline 2000 & 1282 & 883 & 2165 & & 3.49 & 2.57 & 3.04 & & 4.02 & 3.28 & 3.66 & \\
\hline 2005 & 1726 & 1187 & 2913 & & 4.55 & 3.38 & 3.98 & & 5.62 & 4.72 & 5.18 & \\
\hline 2010 & 1775 & 1177 & 2952 & & 4.69 & 3.3 & 4 & & 6.14 & 4.93 & 5.54 & \\
\hline 2015 & 2085 & 1176 & 3261 & & 5.28 & 3.21 & 4.26 & & 7.09 & 5.07 & 6.09 & \\
\hline
\end{tabular}
respectively. 
Table 2. The death and DALYs number of esophageal cancer in different age groups in Iran during1995- 2015

\begin{tabular}{|c|c|c|c|c|c|c|c|c|c|}
\hline \multirow{3}{*}{ Age groups } & \multicolumn{6}{|c|}{ DALYs Number and Rate } & \multicolumn{3}{|c|}{ Death Number } \\
\hline & \multicolumn{2}{|c|}{ Female } & \multicolumn{2}{|c|}{ Male } & \multicolumn{2}{|c|}{ Total } & \multirow[t]{2}{*}{ Female } & \multirow[t]{2}{*}{ Male } & \multirow[t]{2}{*}{ Total } \\
\hline & Number & $\begin{array}{l}\text { Crude Rate } \\
\text { per } 100,000\end{array}$ & Number & $\begin{array}{l}\text { Crude Rate } \\
\text { per } 100,000\end{array}$ & Number & $\begin{array}{l}\text { Crude Rate } \\
\text { per } 100,000\end{array}$ & & & \\
\hline Younger than 5 & 0 & 00 & 0 & 00 & 0 & 00 & 0 & 0 & 0 \\
\hline $5-14$ years & 0 & 00 & 0 & 00 & 0 & 00 & 0 & 0 & 0 \\
\hline $15-49$ years & 31148 & 25.72 & 37587 & 29.06 & 68735 & 27.4 & 678 & 816 & 1494 \\
\hline $50-69$ years & 66003 & 289.66 & 93301 & 397.38 & 159304 & 344.02 & 2409 & 3438 & 5847 \\
\hline$>70$ years & 27389 & 496.8 & 48674 & 788.42 & 76063 & 649.62 & 2092 & 3711 & 5803 \\
\hline All ages & 124540 & 56.93 & 179562 & 78.81 & 304102 & 68.02 & 5178 & 7966 & 13144 \\
\hline
\end{tabular}

Table 3. YLLs and YLDs of esophageal cancer in different age groups in Iran during 1995-2015

\begin{tabular}{|c|c|c|c|c|c|c|c|c|c|}
\hline \multirow[b]{2}{*}{ Age } & \multirow[b]{2}{*}{ Year } & \multicolumn{2}{|c|}{ YLLs } & \multicolumn{2}{|c|}{ YLDs } & \multicolumn{3}{|c|}{ DALYs } & \multirow{2}{*}{$\begin{array}{c}\begin{array}{c}\text { Cochran- } \\
\text { Armitage test }\end{array} \\
\mathrm{Z}=1.8\end{array}$} \\
\hline & & Female & Male & Female & Male & Female & Male & Both & \\
\hline $15-49$ years & 1995 & 5209 & 5311 & 29 & 29 & 5238 & 5340 & 10578 & $P$ value $=0.072$ \\
\hline $50-69$ years & 1995 & 10113 & 14181 & 84 & 117 & 10197 & 14298 & 24495 & \\
\hline$>70$ years & 1995 & 3650 & 6156 & 53 & 86 & 3703 & 6242 & 9945 & \\
\hline All ages & 1995 & 18970 & 25649 & 167 & 232 & 19137 & 25881 & 45018 & \\
\hline $15-49$ years & 2000 & 6178 & 6481 & 40 & 40 & 6218 & 6521 & 12739 & \\
\hline $50-69$ years & 2000 & 11211 & 15387 & 102 & 133 & 11313 & 15520 & 26833 & \\
\hline$>70$ years & 2000 & 4484 & 7560 & 71 & 113 & 4555 & 7673 & 12228 & \\
\hline All ages & 2000 & 21873 & 29427 & 213 & 287 & 22086 & 29714 & 51800 & \\
\hline $15-49$ years & 2005 & 6966 & 8600 & 52 & 60 & 7018 & 8660 & 15680 & \\
\hline $50-69$ years & 2005 & 14190 & 18549 & 139 & 167 & 14329 & 18716 & 33045 & \\
\hline$>70$ years & 2005 & 6756 & 11169 & 113 & 178 & 6869 & 11347 & 18216 & \\
\hline All ages & 2005 & 27912 & 38319 & 304 & 406 & 28216 & 38725 & 66941 & \\
\hline $15-49$ years & 2010 & 6162 & 8185 & 49 & 61 & 6211 & 8246 & 14457 & \\
\hline $50-69$ years & 2010 & 13891 & 18994 & 145 & 182 & 14036 & 19176 & 33212 & \\
\hline$>70$ years & 2010 & 6658 & 11287 & 127 & 203 & 6785 & 11490 & 18275 & \\
\hline All ages & 2010 & 26708 & 38466 & 321 & 447 & 27030 & 38914 & 65944 & \\
\hline $15-49$ years & 2015 & 6408 & 8750 & 54 & 69 & 6462 & 8819 & 15281 & \\
\hline $50-69$ years & 2015 & 15951 & 25346 & 177 & 245 & 16128 & 25591 & 41719 & \\
\hline$>70$ years & 2015 & 5365 & 11701 & 112 & 221 & 5477 & 11922 & 17399 & \\
\hline All ages & 2015 & 27724 & 45798 & 342 & 535 & 28066 & 46333 & 74399 & \\
\hline
\end{tabular}

number of DALYs and death due to esophageal cancer in Iran during 1995- 2015 according to age groups. As presented in the table, 50-69 age group and over 70 years age group had the highest DALYs.

Table 3 and Fig. 1 present the number of DALYs, YLLs, and YLDs regarding esophageal cancer by age and gender in Iran during 1995-2015. In both genders and all ages, the number of DALYs indicates a significant increase from 45018 in 1995 to 74399 in 2015.

Data showed that YLLs are the main contributor to
DALY calculations for all ages and both genders. YLLs were 44619 in 1995 and 73522 in 2015, while they were 399 in 1995 and 877 in 2015. Furthermore, YLLs were higher than YLDs in all years and all group ages.

Our findings demonstrated that the burden of esophageal cancer was higher in males than in females. Also, the overall DALYs for all years and all ages were 179562 for males and 124540 for females (Table 2). As displayed in Fig. 2, the DALY rate per 100000 esophageal cancer cases during 1995-2015 was higher for males than females.

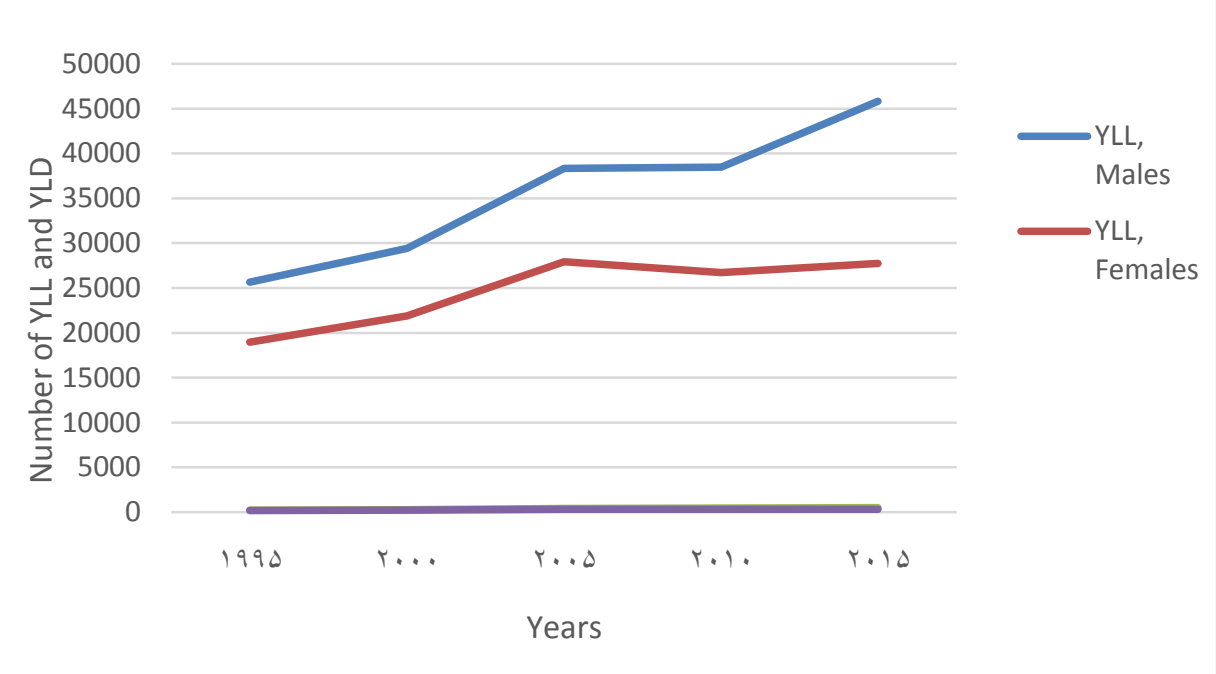

Fig. 1. Sex differentials in burden of esophageal cancer by years in Iran during 1995-2015 


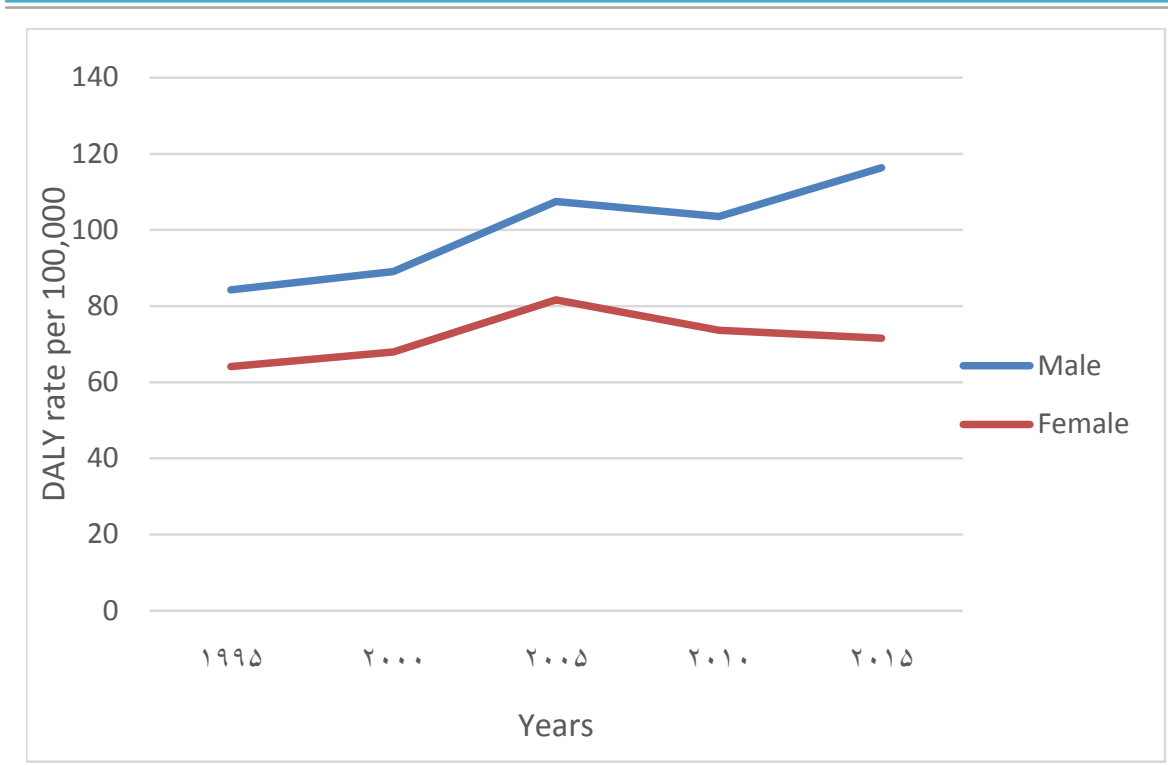

Fig. 2. DALY rate per 100000 for esophageal cancer by sex during 1995-2015 in Iran

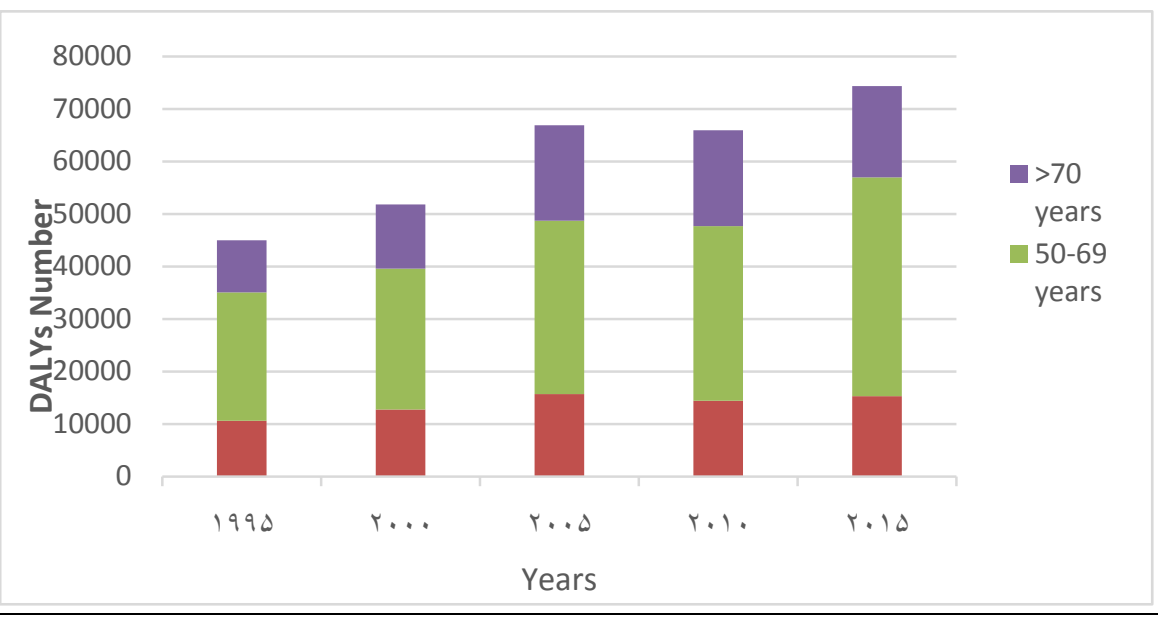

Fig. 3. DALYs number of esophageal cancer in different age groups by years in Iran during 1995-2015

In all age groups, the burden of esophageal cancer was higher in males than in females. Table 3 displays that in 2015 DALYs in all ages were 46333 for males and 28066 for females.

The results of this study indicated that the maximum of DALYs during 1995-2015 was associated with the 50-69 age range for which DALY values were 24495 in 1995 and 41719 in 2015. Figure 3 displays the DALYs for different age groups. As demonstrated, in all years, the 50-69 age groups had the highest DALY due to esophageal cancer in Iran. Furthermore, Table 3 displays the number of DALYs according to sex and age groups. For both genders and all years, the DALYs were higher in 50- 69 age groups than other groups.

\section{Discussion}

The present study was based on GBD findings from 1995 to 2015 for all ages and both genders. Moreover, this study was the first comprehensive effort to report the burden of esophageal cancer in Iran at the general population level.

About 13144 deaths and 304102 DALYs attributed to esophageal cancer were estimated during 1995-2015 in
Iran. The present study clearly showed that DALYs, epidemiological indicators, the number of deaths, and incidence, and prevalence rate of this cancer increased significantly in both genders and all ages in Iran during the period studied. Furthermore, the number of DALYs due to esophageal cancer for both genders was 45018 by all ages in 1995 and 74399 in 2015. Incidence rate per 100000 was 2.7 and 4.26 in 1995 and 2015, respectively. Prevalence rate increased from 2.96 to 6.09 per 100000 during 1995-2015. These findings are consistent with other reports and studies. Darabi et al. estimated that the incidence rate of esophageal cancer increased from 3.25 and 2.1 in 2001 to 5.57 and 5.62 per 100000 in 2010 (13). Another study on the incidence cancer in Iran reported that agestandardized incidence rate per 100000 for males increased from 4.64 to 5.83 during 2003 to 2006 (30). Notably, the burden of esophageal cancer is very high in some areas of Iran, particularly in northeastern parts located on Asian esophageal cancer belt. Regional studies indicate that the incidence and prevalence rate in the mentioned area is higher than other regions and national average. Some studies have shown that the age-standardized incidence rate was more than 43.3 and 36.3 per 100000 in 
males and females, respectively, in the Golestan Province in the north of Iran $(9,31)$.

In line with previous studies, our results indicate that YLL is the main contributor to DALY calculations, as esophageal cancer is a mortal disease. In fact, the burden of fatal diseases predominantly affects premature death. This result is consistent with other studies. For instance, in a study conducted by Sun et al. in China, it was reported that YLLs contributed to $90 \%$ of the DALYs for esophageal cancer (32). Another study reported that YLL contributed to more than $90 \%$ of DALY rate for esophageal cancer in all people (33). Gonzalez-Leon et al. estimated the burden of diseases in Mexico in 2010 and reported that YLL and YLD for esophageal cancer were 6032 and 690, respectively (34).

Our findings also revealed that the burden of esophageal cancer was higher in males than in females for all age groups. During 1995- 2015, the number of deaths was 7967 and 5177 for males and females, respectively, and DALYs number was 179562 for males and 124540 for females. Moreover, DALY rate related to esophageal cancer was higher in males than in females during 19952015 (Fig. 2). Examinations of the DALYs number based on gender and age group (Table 3 ) revealed that the number of DALY was higher in males than in females in all age groups. Several studies have confirmed these results (35-37).

For some reason, the burden of esophageal cancer was higher in males. According to studies conducted in Iran, more than $90 \%$ of esophageal cancers related to squamous cell carcinoma and this subtype of esophageal cancer were associated with tobacco and alcohol consumption, hot food and beverage, ingestion of $\mathrm{N}$-nitroso compounds, smoking, and chewing nass (chewing tobacco mixture). Various studies in Iran have shown that these risk factors are less in females $(16,38-40)$. Moreover, the DALY rate per 100000 during 2005-2015 decreased in females due to several reasons. The death number due to esophageal cancer has increased in females during 1995-2005, but it declined after 2005. Also, the incidence rate shows the same trend (Table 1). In addition, this decline could be due to changes in population structure and the mean age of females, which was less than that of males during the past years. This study showed that $35 \%$ of the changes in esophageal cancer burden during 1990- 2013 can be due to population growth and $35.6 \%$ may be due to change in age structure (41).

The acquired data indicated that the 50- 69 age group had a higher burden of disease than other groups in Iran during 1995-2015. The DALYs number for this group was 24495 and 41719 in 1995 and 2015, respectively. Number of DALYs was 0 for younger than 14 age group in all years. A study in China reported that patients aged 40 to 80 years account for more than $90 \%$ of total esophageal cancer DALYs (32). Studies in Iran have shown that the highest incidence of esophageal cancer is in the sixth decade of life (42-44).

There were some limitations in this study. First, GBD study does not distinguish between the burden of esophageal cancer due to adenocarcinoma of the esophagus and esophageal squamous cell carcinoma. This could be a subject for future studies, as each of these burdens has its own burden of disease. Second, the estimates of GBD study depend on the quality and quantity of the available data sources because of the lag time for data reporting. The burden of cancers could not be estimated for countries that do not have a comprehensive system for registering and reporting cancers. For example, studies have shown that incidence and prevalence of esophageal cancer were much higher than estimates of GBD study in some regions of Iran $(9,45)$.

\section{Conclusion}

Esophageal cancer is still a public health problem in Iran. The majority of DALYs were due to years of life lost (YLL), suggesting the need for prevention, early detection, and screening programs. Since the findings of this study and those of others have shown that the burden of esophageal cancer is greater in the 50-69 age group and given that the young Iranian population is approaching the at-risk age group, policymakers should evaluate the future tasks among different health care sections by considering prevention, early detection, approaching, and rehabilitation.

\section{Acknowledgment}

We thank the Institute for Health Metric and Evaluation (IHME) team for providing the data of GBD studies.

\section{Conflict of Interests}

The authors declare that they have no competing interests.

\section{References}

1. Ferlay J, Soerjomataram I, Dikshit R, Eser S, Mathers C, Rebelo M, et al. Cancer incidence and mortality worldwide: sources, methods and major patterns in GLOBOCAN 2012. Int $\mathbf{J}$ Cancer. 2015;136(5):E359-E86.

2. Global Burden of Disease Study 2015. [Internet]. 2015 [cited Available from http://ghdx.healthdata.org/gbd-results-tool.].

3. Arnold M, Laversanne M, Brown LM, Devesa SS, Bray F. Predicting the Future Burden of Esophageal Cancer by Histological Subtype: International Trends in Incidence up to 2030. Am J Gastroenterol. 2017.

4. Conteduca V, Sansonno D, Ingravallo G, Marangi S, Russi S, Lauletta G, et al. Barrett's esophagus and esophageal cancer: an overview. Int J Oncol. 2012;41(2):414-24.

5. Mansour-Ghanaei F, Heidarzadeh A, Naghipour MR, Joukar F, Valeshabad AK, Fallah MS, et al. A 10-year study of esophageal cancer in Guilan Province, Iran: the guilan cancer registry study (GCRS). Asian Pac J Cancer Prev. 2012;13(12):6277-83.

6. Islami F, Malekshah AF, Kimiagar M, Pourshams A, Wakefield J, Goglani G, et al. Patterns of food and nutrient consumption in northern Iran, a high-risk area for esophageal cancer. Nutr Cancer. 2009;61(4):475-83.

7. Islami F, Kamangar F, Nasrollahzadeh D, Aghcheli K, Sotoudeh M, Abedi-Ardekani B, et al. Socio-economic status and oesophageal cancer: results from a population-based case-control study in a highrisk area. Int J Epidemiol. 2009;38(4):978-88.

8. Semnani S, Sadjadi A, Fahimi S, Nouraie M, Naeimi M, Kabir J, et al. Declining incidence of esophageal cancer in the Turkmen Plain, eastern part of the Caspian Littoral of Iran: a retrospective cancer surveillance. Cancer Detect Prev. 2006;30(1):14-9.

9. Sadjadi A, Marjani H, Semnani S, Nasseri-Moghaddam S Esophageal cancer in Iran: A review. 
Middle East J Cancer. 2010;1(1):5-14.

10. Harirchi I, Kolahdoozan S, Hajizadeh S, Safari F, Sedighi Z, Nahvijou A, et al. Esophageal cancer in Iran; a population-based study regarding adequacy of cancer surgery and overall survival. Eur J Surg Oncol (EJSO). 2014;40(3):352-7.

11. Mir MR, Rajabpour MV, Delarestaghi MM, Hadji M, Harirchi I, Mir P, et al. Short-and long-term survival of esophageal cancer patients treated at the Cancer Institute of Iran. Dig Surg. 2013;30(46):331-6.

12. De Angelis R, Sant M, Coleman MP, Francisci S, Baili P, Pierannunzio D, et al. Cancer survival in Europe 1999-2007 by country and age: results of EUROCARE-5 - a population-based study. Lancet Oncol. 2014:15(1):23-34.

13. Darabi M, Lari MA, Motevalian SA, Motlagh A, Arsang-Jang S, Jaberi MK. Trends in gastrointestinal cancer incidence in Iran, 20012010: a joinpoint analysis. Epidemiol Health. 2016;38.

14. Almasi Z, Mohammadian-Hafshejani A, Salehiniya H. Incidence, mortality, and epidemiological aspects of cancers in Iran; differences with the world data. J BUON. 2016;21(4):994-1004.

15. Momenyan S, Sadeghifar M, Sarvi F, Khodadost M, MosaviJarrahi A, Ghaffari ME, et al. Relationship between Urbanization and Cancer Incidence in Iran Using Quantile Regression. Asian Pac. J. Cancer Prev. 2016;17(S3):113-7.

16. Mosavi-Jarrahi A, Mohagheghi MA. Epidemiology of esophageal cancer in the high-risk population of Iran. Asian Pac. J. Cancer Prev. 2006;7(3):375.

17. Mousavi SM, Somi MH. Gastric cancer in Iran 1966-2006. Asian Pac. J. Cancer Prev. 2009;10(3):407-12.

18. Salehi M, Ahmadi E, Roshandel G, Heidarnia M, Keshtkar A, Sajadi A, et al. Total Burden of Esophageal Cancer Disability Adjusted Life Years in Golestan Province during 1387. Govaresh. 2011;15(4):276-82.

19. Murray CJ, Vos T, Lozano R, Naghavi M, Flaxman AD, Michaud C, et al. Disability-adjusted life years (DALYs) for 291 diseases and injuries in 21 regions, 1990-2010: a systematic analysis for the Global Burden of Disease Study 2010. lancet. 2013;380(9859):2197223.

20. Wang H, Dwyer-Lindgren L, Lofgren KT, Rajaratnam JK, Marcus JR, Levin-Rector A, et al. Age-specific and sex-specific mortality in 187 countries, 1970-2010: a systematic analysis for the Global Burden of Disease Study 2010. Lancet. 2013;380(9859):2071-94.

21. Lopez AD, Mathers CD. Measuring the global burden of disease and epidemiological transitions: 2002-2030. Ann Trop Med Parasitol. 2006;100(5-6):481-99.

22. Lopez A, Mathers C, Ezzati M, Jamison D, Murray C. Global Burden of Disease and Risk Factors: A copublication of Oxford University Press and The World Bank. 2006.

23. WHO methods and data sources for global burden of disease estimates 2000-2015. Department of Information EaRW, Geneva; 2017.

24. Murray CJ, Lopez AD, Jamison DT. The global burden of disease in 1990: summary results, sensitivity analysis and future directions. Bull. World Health Organ. 1994;72(3):495.

25. Sassi F. Calculating QALYs and DALYs: methods and applications to fatal and non-fatal conditions. Handbook of Disease Burdens and Quality of Life Measures: Springer; 2010. p. 313-28.

26. Lopez AD. Global burden of disease and risk factors: World Bank Publications; 2006.

27. WHO G. WHO methods and data sources for global burden of disease estimates 2000-2011. Geneva: Department of Health Statistics and Information Systems. 2013.

28. Gabbe BJ, Lyons RA, Simpson PM, Rivara FP, Ameratunga S, Polinder S, et al. Disability weights based on patient-reported data from a multinational injury cohort. Bull. World Health Organ. 2016;94(11):806.

29. Ahmad OB, Boschi-Pinto C, Lopez AD, Murray CJ, Lozano R, Inoue M. Age standardization of rates: a new WHO standard. Geneva: World Health Organization. 2001;9.

30. Mousavi SM, Gouya MM, Ramazani R, Davanlou M, Hajsadeghi $N$, Seddighi Z. Cancer incidence and mortality in Iran. Ann. Oncol. 2009;20(3):556-63.

31. Kamangar F, Malekzadeh R, Dawsey SM, Saidi F. Esophageal cancer in Northeastern Iran: a review. Arch Iran Med. 2007;10(1):70-82.

32. Sun X, Zhao D, Liu Y, Liu Y, Yuan Z, Wang J, et al. The long- term spatial-temporal trends and burden of esophageal cancer in one high-risk area: A population-registered study in Feicheng, China PLoS ONE. 2017;12(3):e0173211.

33. Jayatilleke N, Pashayan N, Powles J. Burden of disease due to cancer in England and Wales. $J$ Public Health (Oxf) 2012;34(2):287-95.

34. González-León M, Fernández-Gárate JE, Rascón-Pacheco RA, Valladares-Aranda MÁ, Dávila-Torres J, Borja-Aburto VH. The burden of disease of cancer in the Mexican Social Security Institute. Salud Publica Mex. 2016;58(2):132-41.

35. Traebert J, Schneider IJC, Colussi CF, de Lacerda JT. Burden of disease due to cancer in a Southern Brazilian state. Cancer Epidemiol. 2013;37(6):788-92.

36. Chen W, He Y, Zheng R, Zhang S, Zeng H, Zou X, et al Esophageal cancer incidence and mortality in China, 2009. J Thorac Dis. 2013;5(1):19-26.

37. Fitzmaurice C, Allen C, Barber RM, Barregard L, Bhutta ZA, Brenner $\mathrm{H}$, et al. Global, regional, and national cancer incidence, mortality, years of life lost, years lived with disability, and disabilityadjusted life-years for 32 cancer groups, 1990 to 2015: a systematic analysis for the global burden of disease study. JAMA Oncol. 2017;3(4):524-48.

38. Malekzadeh R, Derakhshan MH, Malekzadeh Z. Gastric cancer in Iran: epidemiology and risk factors. Arch Iran Med. 2009;12(6):57683.

39. Sepehr A, Kamangar F, Fahimi S, Saidi F, Abnet CC, Dawsey SM. Poor oral health as a risk factor for esophageal squamous dysplasia in northeastern Iran. Anticancer Res. 2005;25(1B):543-6.

40. Islami F, Pourshams A, Nasrollahzadeh D, Kamangar F, Fahimi S, Shakeri R, et al. Tea drinking habits and oesophageal cancer in a high risk area in northern Iran: population based case-control study. Bmj. 2009;338:b929.

41. Fitzmaurice C, Dicker D, Pain A, Hamavid H, Moradi-Lakeh M, MacIntyre MF, et al. The global burden of cancer 2013 . JAMA Oncol. 2015;1(4):505-27.

42. Semnani Sh, Arabali A, Keshtkar A, Behnampoor N. Nitrate and nitrite level of drinking water and the risk of upper gastrointestinal cancers in urban areas of Golestan province, northeast of Iran JKMU. 2015

43. Semnani S, Besharat S, Abdolahi N, Keshtkar A, Kabir M, Fazel A, et al. Factors associated with esophageal cancer in the southeast part of the Caspian Sea. Jour guilan uni med sci. 2005;13(52):24-8.

44. Samadi F, Babaei M, Yazdanbod A, Fallah M, Nouraie M, Nasrollahzadeh D, et al. Survival rate of gastric and esophageal cancers in Ardabil province, North-West of Iran. Arch Iran Med. 2007;10(1):32-7.

45. Radmard AR. Five common cancers in Iran. Arch Iran Med 2010;13(2):143. 